\title{
Identification of Best Split Application Frequency and Timing of Nitrogen Fertilizer for Sorghum (Sorghum bicolor) in Eastern Amhara
}

\author{
Kassa Sisay Aragaw* Habtemariam Teshome Abush Samuel Adissie Gedamu Tadesse Hailu Shibeshi \\ ${ }^{1}$ Sirinka Agricultural Research Center, ${ }^{2}$ Amhara Regional Agricultural Research Institute (ARARI) \\ Corresponding: Kassa Sisay Aragaw Sirinka Agricultural Research Center, P.O. Box 74, Woldia
}

\begin{abstract}
Nitrogen is one of the growth limiting nutrients in agricultural production. Proper nitrogen application time and rates are critical to meet crop needs and indicate considerable opportunities for improving nitrogen use efficiency. Split-application of Nitrogen fertilizer experiment was conducted in major long mature sorghum varieties (Degalet \& Jamyo) growing areas of Eastern Amhara for 2016/17 cropping season. The experiment was initiated to identify the appropriate time and frequency of $\mathrm{N}$ fertilizer application on grain yield of long mature sorghum. The experiment was designed in randomized complete block consisting of five Nitrogen fertilizer application times: (1) $1 / 2$ at planting $+1 / 2$ at knee height stage, (2) $1 / 3$ at planting $+1 / 3$ at knee height stage $+1 / 3$ at stem elongation (3) $2 / 3$ at knee height $+1 / 3$ at stem elongation, (4) $1 / 3$ at planting $+2 / 3$ at knee height stage and (5) full recommended $\mathrm{N}$ at Knee height stage of the crop and replicated three times in each farmer's field . The collected data were subjected to analysis of variance using SAS version 9.0. The Result showed that there was no statistical significance yield difference $(\mathrm{p}>0.05)$ between treatments in both Raya Kobo and srinka for the two long maturity sorghum (degalet and jamyo) varieties.
\end{abstract}

Keywords: Fertilizer, Nitrogen, Sorghum, Split application

DOI: $10.7176 / \mathrm{JEES} / 10-6-03$

Publication date:June $30^{\text {th }} 2020$

\section{Introduction}

Sorghum (Sorghum bicolor (L.) Moench) is the most important cereal crop in Ethiopia ranking third in area coverage after tef and maize. In Amhara region, sorghum covered a significant amount of cultivated land following tef. Kobo and Srinka is one of the potential areas of North Wollo zone where sorghum is largely produced. Despite its importance, sorghum productivity and production remained very low owing to different biotic and abiotic production constraints. Moisture stress, low soil fertility, poor crop management practices for instance timing of nitrogen fertilizer application and sorghum pests are the major sorghum production constraints (Gebreyesus Brhane, 2012). Erratic and unreliable rainfall is the most serious physical constraint for sorghum production in dry land areas as compared to timing of Urea fertilizer application (Aleminew et al., 2015).

Proper nitrogen application time and rates are critical to meet crop needs and indicate considerable opportunities for improving nitrogen use efficiency. The most commonly used practice in improving nitrogen use efficiency of crops is split application of fertilizers, selection of crop growth environment (soil type and climate) and management practices (sowing date and rate of nitrogen application). Application of nitrogen in split form worth's a lot than applying the whole doze at once; however, there are many challenges that hinder effectiveness of this practice such as availability of soil moisture during the time of nitrogen application (Mesfn et al., 2009)

Thus, the time and rate of $\mathrm{N}$ application are critical management decisions because they can influence the Nfertilizer uptake efficiency (Alcoz et al., 1993). However, appropriate time and frequency of split application of $\mathrm{N}$ depends on weather, soil and crop type and type of fertilizer used. In most cases of dry land areas, the main bottle neck was lack of early rain fall distribution especially at planting time in the months of April to May. It is therefore justifiable to conclude that there should be location specific Urea fertilizer application timing especially for sorghum varieties. Recently, BOA is advocating application of $\mathrm{N}$ fertilizer to be made only once after emergency while abandoning split application and addition of urea fertilizer at planting. However, this justification is not supported by a kind of result obtained from a scientifically conducted field experiment, particularly in our research mandate area. Therefore, this research was initiated with the objective of determining the appropriate time and frequency of $\mathrm{N}$ fertilizer application for long mature sorghum crops.

\section{MATERIALS AND METHODS}

\subsection{Study sites}

The experiment was conducted on two sites of sorghum growing areas of Habru (Sirinka) and Raya Kobo districts for long mature sorghum on- five farmer's field at Srinka, four farmer's field in Raya Kobo in 2016/17 cropping year and two farmer's field in 2018 at Srinka. The study site, Sirinka, is located about $508 \mathrm{~km}$ away from Addis Ababa, the capital city of Ethiopia, in the north east direction at an altitude of 1850 meters above sea level and at 
$11^{0} 45^{\prime} 00^{\prime \prime} \mathrm{N}$ latitude and $39^{\circ} 36^{\prime} 36^{\prime \prime} \mathrm{E}$ longitude. The average annual rainfall of the study area was $945 \mathrm{~mm}$ and the mean maximum and minimum temperatures were 26 and $13^{\circ} \mathrm{C}$, respectively. The dominant soil type in the study area, based on the FAO/UNESCO System is Eutric Vertisols. The geographical location of Raya-Kobo district lies between $12^{\circ} 08^{\prime} \mathrm{N}$ latitude and $39^{\circ} 28^{\prime} \mathrm{E}$ longitude and elevation of $1468 \mathrm{~m}$ above sea level (masl) in North Wollo zone of Amhara National Regional State. The district receives a mean annual rainfall, maximum and minimum temperature of $630 \mathrm{~mm}, 29^{\circ} \mathrm{C}$ and $15^{\circ} \mathrm{C}$ respectively with considerable year to year variation. The area is characterized by seasonal moisture stress and erratic rainfall.

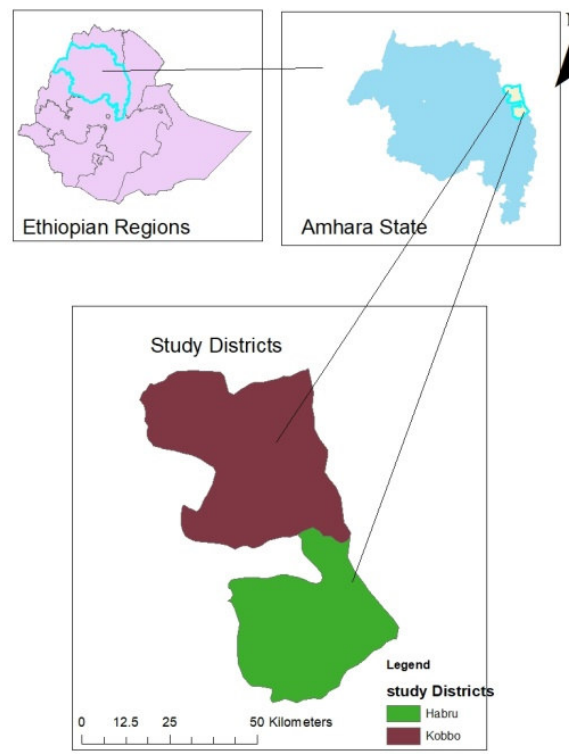

Figure 1: Map of The Study districts

\subsubsection{Rain fall}

The rain fall distribution of Raya kobo and Habru (sirinka) were displayed in the following Figures.

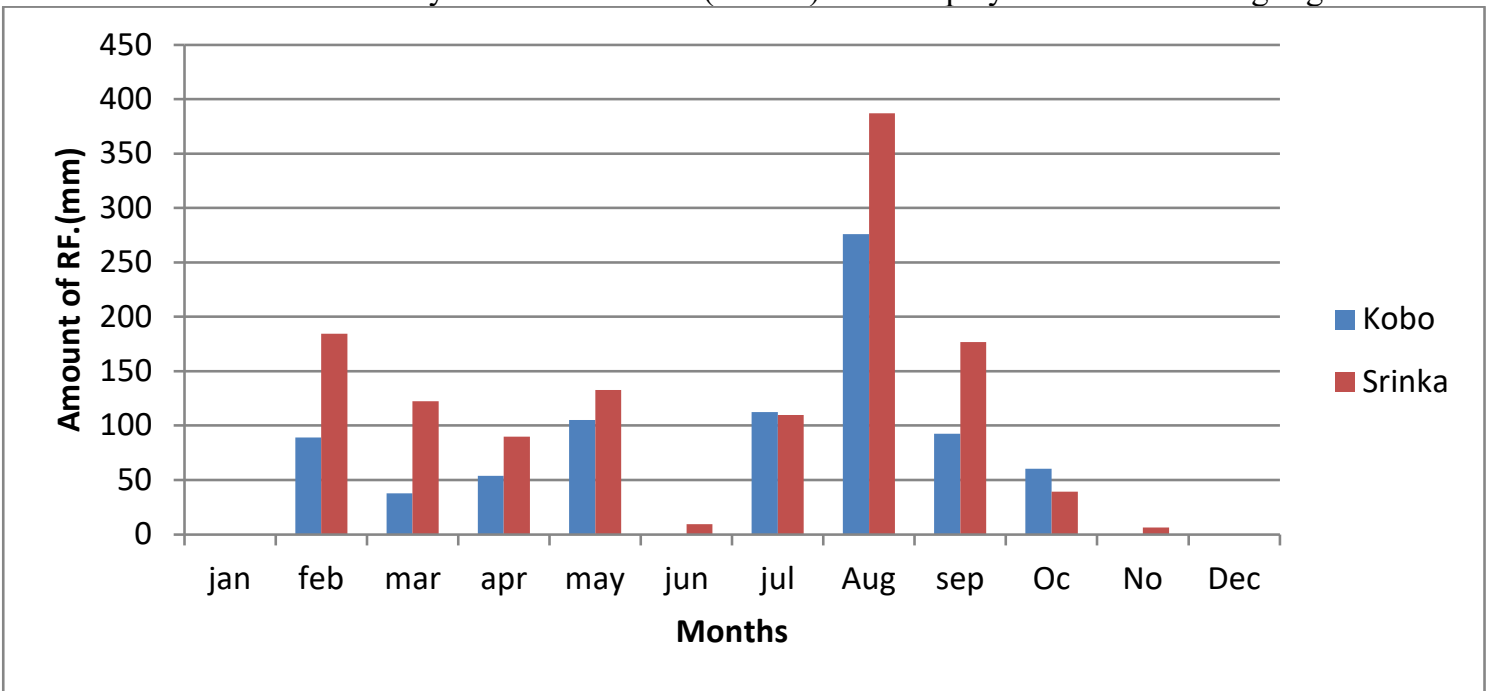

Figure 2: Monthly Rain fall of the study district in 2017cropping season 


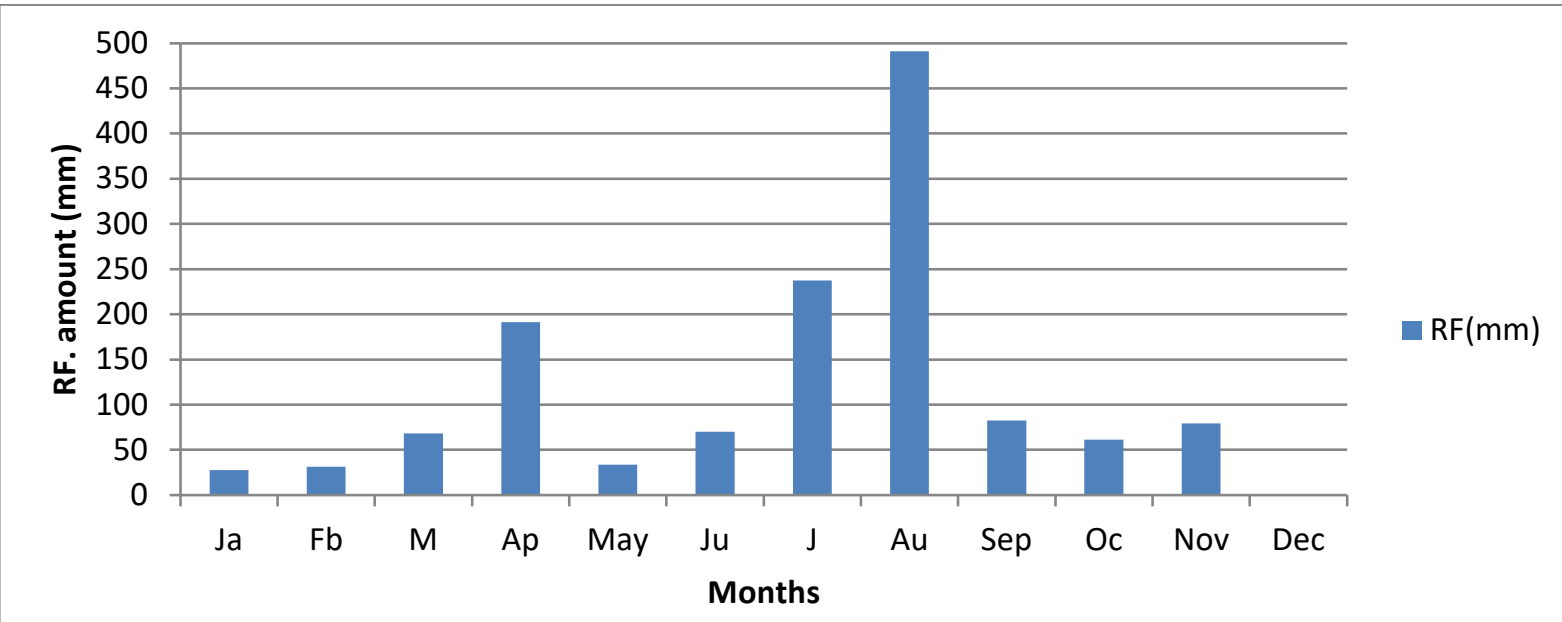

Figure 3: Monthly Rainfall of srinka in 2018

\subsection{Treatment setup and Design}

The experimental design was randomized complete block design consisting of five Nitrogen application times: (1) $1 / 2$ at planting $+1 / 2$ at knee height stage, (2) $1 / 3$ at planting $+1 / 3$ at knee height stage $+1 / 3$ at stem elongation (3) $2 / 3$ at knee height $+1 / 3$ at stem elongation, (4) $1 / 3$ at planting $+2 / 3$ at knee height stage and (5) full recommended $\mathrm{N}$ at Knee height stage of the crop and replicated three times in each farmer's field .

Sorghum was planted with spacing of $75 \mathrm{~cm}$ between rows and $15 \mathrm{~cm}$ between plants. The spacing between replications and between plots was $1 \mathrm{~m}$ and $0.5 \mathrm{~m}$, respectively. Plot size of the experiment was $4.8 \mathrm{~m} \mathrm{x} 3 \mathrm{~m}$ and net harvested rows were four rows from the six rows of the plot. Basal application of $69 \mathrm{~kg} / \mathrm{ha}_{2} \mathrm{O}_{5}$ was applied at planting for each plot. TSP, DAP and urea fertilizer were used as a source of phosphorous and nitrogen fertilizer. Proper agronomic practices were applied as recommended. The long maturing varieties Degalet and Jamyo were used as planting materials for this experiment. Karatin was sprayed for the protection of ball army worm.

\subsection{Soil sampling collection}

An initial composite soil sample were taken at a depth of 0-20 cm from each farmers field before sowing in a zigzag pattern randomly from the experimental field using soil auger. Composite samples were prepared for analysis to determine the soil physico-chemical properties of the experimental site at Srinka agricultural research center Soil Laboratory. The collected Samples were air-dried and ground to pass a 2-mm sieve and $0.5 \mathrm{~mm}$ sieve (for total $\mathrm{N}$ ) before analysis. Soil texture was determined by Bouyoucos hydrometer method. The $\mathrm{pH}$ of the soils was measured in water (1:2.5 soils to water ratio). The organic carbon content of the soil was determined following Walkley and Black procedures (1934). The total nitrogen was also determined by Kjeldahl method (Bremner \& Mulvaney, 1982).

\subsection{Yield data collection}

Yield data was collected from the central rows while, the two border rows were not included. The moisture content of the grain was collected at the same time with the grain yield and finally adjusted to the moisture content of $12.5 \%$. Dry biomass weight was measured by weighing the fresh total above ground biomass of the harvestable rows and adjusted by taking random samples and oven drying it.

\subsection{Data Analysis}

The collected data were subjected to analysis of variance using SAS version 9.0Soft ware. Whenever treatment effects was significant, the means was separated using the least significant difference (LSD) procedures test at $5 \%$ level of significance.

\section{Results and Discussion}

\subsection{Physicochemical properties of the soil}

Results of pre-sowing soil analysis showed that soils of the experimental sites were silt clay in texture (Table 1). The total nitrogen ranged from $0.08 \%$ to $0.13 \%$ and $0.1 \%$ to $0.25 \%$ for Raya Kobo and srinka respectively, and this range is medium for srinka and low level for Kobo district (Tekaligne et al., 1991). The soil organic matter ranges from $1.86 \%$ to $2.8 \%$ in Raya Kobo which was considered as low to medium level and in srinka it ranges from $0.88 \%$ to $2.0 \%$, which is also categorized under low content of organic matter according to Berhanu 
(1980). The soil reaction $(\mathrm{pH})$ of the two districts was ranging from 6.7 to 6.9 and 6.4 to 6.8 for Kobo Raya and srinka study areas respectively.

The soil analysis result of Srinka in line with characterization of SARC main station studies which states majority of the surface and sub-soil layers of SARC main research station vary from clay to heavy clay, $\mathrm{pH}$ of most of the area is in the neutral range, The organic matter content of the surface soil falls in the low range and The total $\mathrm{N}$ content of the surface soil falls in the low to medium range (Abebe et al., 2016 unpublished).

Table 2: value of some parameters of soil samples taken at planting at Sirinka and Raya-Kobo.

\begin{tabular}{lcccc}
\hline Site & $\mathrm{pH}$ & $\% \mathrm{OM}$ & $\% \mathrm{~T} . \mathrm{N}$ & Textural class \\
\hline Raya kobo & $6.7-6.9$ & $1.86-2.8$ & $0.08-0.13$ & Silt clay \\
Srinka & $6.4-6.8$ & $0.88-2.0$ & $0.1-0.25$ & Silt clay \\
\hline
\end{tabular}

Note: $\mathrm{pH}=$ power of Hydrogen; $\% \mathrm{OM}=$ percentage of organic matter; $\% \mathrm{~T} . \mathrm{N}=$ percentage of total nitrogen;

\subsection{Yield Response of Sorghum}

According to the study results, Split application of nitrogen at different growth stages of sorghum didn't brought a statistically significant yield difference $(\mathrm{P}>0.05)$ in grain and biomass yield (Table $2 \& 3)$ for Srinka and Raya Kobo for the two long mature sorghum (Degalet and Jamyo) varieties. The regional bureau of agriculture reported that application of nitrogen half at planting and half at knee height were not increase production and productivity of sorghum. This could be due to that the rate of nitrogen that was used for split at different growth stage was equal but the nitrogen requirements for different growth stage could not be similar.

Table 3: Effect of timing and frequency of $\mathrm{N}$ fertilizer on sorghum yield $\left(\mathrm{kgha}^{-1}\right)$ at Raya-Kobo

\begin{tabular}{lcccc}
\hline Treatment & \multicolumn{2}{c}{ Degalet } & Grain yield & Biomass \\
\hline split & Grain yield & Biomass & 4609.7 & 14598 \\
$1 / 3 \mathrm{p}, \mathrm{k}, \mathrm{s}$ & 4975 & 19155 & 4795 & 14369 \\
$1 / 3 \mathrm{p} .2 / 3 \mathrm{k}$ & 4323 & 18052 & 4745.7 & 15536 \\
$2 / 3 \mathrm{k}-1 / 3 \mathrm{~s}$ & 4591 & 19900 & 4557.6 & 16521 \\
F.k & 4858 & 18877 & 4426.7 & 14670 \\
\hline LSD (5\%) & 4405 & 18467 & $\mathrm{NS}$ & $\mathrm{NS}$ \\
CV $(\%)$ & $\mathrm{NS}$ & $\mathrm{NS}$ & 21.2 & 11.78 \\
\hline
\end{tabular}

Note; $\mathrm{P}=$ planting, $\mathrm{k}=$ kee height, f. $\mathrm{k}=$ full at knee height and $\mathrm{s}=$ steam elongation

Table 4: Effect of timing \& frequency of $\mathrm{N}$ fertilizer on sorghum yield $\left(\mathrm{kgha}^{-1}\right)$ at Srinka

\begin{tabular}{lcccc}
\hline Treatment & \multicolumn{2}{c}{ Degalet } & Yield & Bamyomass \\
\cline { 2 - 5 } & Yield & Biomass & 4475 & 14289 \\
split & 4535 & 15700 & 4486 & 13341 \\
$1 / 3 \mathrm{p}, \mathrm{k}, \mathrm{s}$ & 4087 & 15558 & 4659 & 13755 \\
$1 / 3 \mathrm{p} .2 / 3 \mathrm{k}$ & 4175 & 14680 & 4252 & 13052 \\
$2 / 3 \mathrm{k}-1 / 3 \mathrm{~s}$ & 4207 & 15391 & 4462 & 13320 \\
F.k & 4255 & 15514 & $\mathrm{NS}$ & $\mathrm{NS}$ \\
\hline LSD (5\%) & $\mathrm{NS}$ & $\mathrm{NS}$ & 16.1 & 14.2 \\
CV (\%) & 16.8 & 17.9 & \\
\hline
\end{tabular}

Note; $\mathrm{P}=$ planting, $\mathrm{k}=\mathrm{knee}$ height, $\mathrm{f} . \mathrm{k}=$ full at knee height and $\mathrm{s}=$ steam elongation

The result (Table 4) indicates that even if the yield is lower, there is no significant Yield difference between treatments. As observed in the Table below the yield data were very low as compared to the previous year yield result (Table 3). This was due to that in the 2018 cropping season there was high infestation of ball army worms in the district, during the vegetative stage of the crop.

Table 5: Effect of timing \& frequency of $\mathrm{N}$ fertilizer on sorghum yield $\left(\mathrm{kgha}^{-1}\right)$ at Srinka in 2018.

\begin{tabular}{|c|c|c|c|c|}
\hline \multirow[t]{2}{*}{ Treatment } & \multicolumn{2}{|c|}{ Degalet } & \multicolumn{2}{|c|}{ Jamyo } \\
\hline & Yield & Biomass & Yield & Biomass \\
\hline split & 1821 & 18893 & 3475 & 16167 \\
\hline $1 / 3 \mathrm{p}, \mathrm{k}, \mathrm{s}$ & 2083 & 17584 & 3160 & 15820 \\
\hline $1 / 3 \mathrm{p} .2 / 3 \mathrm{k}$ & 1889 & 18405 & 3060 & 16114 \\
\hline $2 / 3 \mathrm{k}-1 / 3 \mathrm{~s}$ & 1644 & 15890 & 3273 & 17185 \\
\hline F.k & 1964 & 17812 & 3124 & 16592 \\
\hline LSD (5\%) & $\mathrm{NS}$ & $\mathrm{NS}$ & NS & NS \\
\hline CV (\%) & 23.6 & 12.6 & 22.1 & 16.4 \\
\hline
\end{tabular}

Note; $\mathrm{P}=$ planting, $\mathrm{k}=$ knee height, $\mathrm{f} . \mathrm{k}=$ full at knee height and $\mathrm{s}=$ steam elongation

During investigation of this research the two varieties showed similar performance from emergency up to 
harvesting with respect to nitrogen application time. This may be due to that the varieties (Degalet and Jamyo) are genetically similar so that different response to time of nitrogen fertilizer not expected in their performance. Split application of nitrogen fertilizer helps the farmers get more benefits from application of fertilizer investment and to reduce loss of fertilizer during application. In the study area application of fertilizer particularly nitrogen is done once at knee height of the crop growth stages if the performance of the crop is poor otherwise fertilizer is not applied for long mature sorghum.

This finding is in line with Gebremedhin Gebrekiros, et al. (2016) who revealed that the yield gained from application of nitrogen at different growth stage is similar or no yield increment. Chibsa, et al., 2016 also stated that applications of full rate of nitrogen at planting and two split applications timing give similar grain yield of durum wheat. This study disagreed with the findings of Alemnew et al ,(2015) which states that for improved and local (Jiguritie) variety of sorghum application of nitrogen at $1 / 2$ after thinning $+1 / 2$ at knee height stage could increase yield of sorghum at Kobo and Sirinka by monitoring the moisture content of the area. Time of nitrogen application had positive effect on yield attributes of maize (Kwaga, 2014, Raouf Seyed Sharif and Ali Namvar, 2016; Tilahun Tadesse et al, 2013). Application of nitrogen fertilizer half at planting and half at knee height stage with proper management increases sorghum yield at Gumeramakesegnit (Nigus Demelash, et al, 2017).

Split-application of nitrogen is best method to reduce loss of this nutrient and it is better than applying the whole amount at once; because availability of soil moisture during the time of nitrogen application could affect. Generally it is better to apply nitrogen fertilizer by monitoring the moisture content of the farm to increase its effectiveness. It is clear that the importance of split application nitrogen fertilizer for the production of crops, however; with the current status of sorghum responses for the study districts and other similar areas with similar soil and agro ecological properties application of equal amount of nitrogen at different growth stages doesn't give any difference in biological yield.

\section{Conclusion and Recommendations}

This result revealed that application of nitrogen at different growth stages of sorghum didn't brought a statistically significant difference in both grain yield and biomass yield of long mature sorghum varieties in the two sorghum growing areas. Based on this finding, Rain fall amount during the time of planting and by considering the nature of fertilizer with moisture and farming system of the farmer's in the district full rate of nitrogen at knee height should be used. But further research should be done using different rates of nitrogen based on the available moisture content of the soil, which helps to know the nitrogen sensitive growth stage of the crop and appropriate timing of nitrogen fertilizer rather than crop growth stage to reach at strong conclusions.

\section{Reference}

Aleminew Amare (2015) Yield Response of Local Long Maturing Sorghum Varieties to Timing of Nitrogen Fertilizer Application in Eastern Amhara Region, Ethiopia. Sirinka Agricultural Research Center. Journal of Biology Agriculture and Healthcare 6: 1

Berhanu Debele. 1980. The physical criteria and their rating proposed for land evaluation in the highland region of Ethiopia. Land use planning and regulatory department, Ministry of Agriculture. Addis Ababa, Ethiopia.

Bremner, J. M., \& Mulvaney, C. S. (1982). Nitrogen-total. In Methods of soil analysis. Part 2. Chemical and microbiological properties, (methodsofsoilan2) (pp. 595-624).

Gebremedhin G, Tariku E, Wslassie M, Dargie S (2016) Response of Grain Sorghum to Split Application of Nitrogen at Tanqua Abergelle Wereda, North Ethiopia. J Fertil Pestic 7: 168.

Nigus Demelash Melaku, Wondimu Bayu, Feras Ziadat, Stefan Strohmeier, Claudio Zucca, Meron Lakew Tefera, Baye Ayalew \& Andreas Klik(2017): Effect of nitrogen fertilizer rate and timing on sorghum productivity in Ethiopian highland Vertisols, Archives of Agronomy and Soil Science.

Raouf Seyed Sharif and Ali Namvar, 2016 Effects of time and rate of nitrogen application on phenology and some agronomical traits of maize.

Tewodros Mesfin, Gebreyesus Brhane Tesfahunegn, C.S. Wortmann, O. Nikus and M. Mamo, 2009. Tied ridging and fertilizer use for sorghum production in semi-arid Ethiopia. Nutr. Cycl. Agroecosys., 85:87-94.

Tilahun- Chibsa B, Heluf Gebrekidan, Kibebew- Kibret T. and Tolessa- Debele D.Effect of rate and time of nitrogen fertilizer application on durum wheat (Triticum turgidum Var L. Durum) grown on Vertisols of Bale highlands, southeastern Ethiopia.

Tilahun Tadesse, Alemayehu Assefa, Minale Liben Momona and Zelalem Tadesse, 2013. Effects of nitrogen split application on productivity, nitrogen use efficiency and economic benefits of maize production in Ethiopia. International Journal of Agricultural Policy and Research, 1(4).

Walkley, A., \& Black, I. A. (1934). An examination of the Degtjareff method for determining soil organic matter, and a proposed modifcation of the chromic acid titration method. Soil Science, 37, 29-38. 